\title{
MIRADA CRÍTICA AL INTENTO DE UNIFICACIÓN DE LA RESPONSABILIDAD CIVIL EN EL NUEVO CÓDIGO CIVIL Y COMERCIAL ARGENTINO*
}

\author{
CRITICAL VIEW OF THE ATTEMPT OF UNIFICATION OF \\ THE CIVIL LIABILITY IN THE NEW ARGENTINIAN CIVIL \\ AND COMMERCIAL CODE
}

\author{
CARLOS PIZARRO WILSON** \\ Profesor de Derecho Civil \\ Universidad Diego Portales \\ Santiago - Chile
}

\section{RESUMEN}

En las siguientes líneas se critica el afán de unificar los regímenes de responsabilidad civil, entendiendo que lo extracontractual y lo contractual puedan convivir en armonía en un régimen común, mas, con todo, hay una diferencia $a b$ initio insuperable: el interés del contrato en lo contractual como una forma de distribuir riesgos según los intereses de las partes; en cambio, la reparación de los bienes afectados de la víctima en materia extracontractual, se conoce como el interés de conservación de los bienes. Se darán algunas

\footnotetext{
*El presente trabajo corresponde a una conferencia presentada en el XIII Congreso Internacional de Daños organizado por la Facultad de Derecho de la Universidad de Buenos Aires (Argentina), 15 y 16 de septiembre de 2016. Hemos mantenido en gran medida el tono coloquial de lo dicho en esa oportunidad, agregando nada más citas esenciales.

** Profesor Investigador Facultad de Derecho de la Universidad Diego Portales, Santiago, Chile. Doctor en Derecho, Universidad Paris II (Panthéon-Assas), Correspondencia a: República 112, Santiago. Correo electrónico: carlos.pizarro@udp.cl .Artículo recibido el 4 de abril de 2017 y aceptado para su publicación el 25 de mayo de 2017.
} 
notas históricas y se expondrá brevemente cómo se expresó la unificación en el nuevo Código Civil argentino, para terminar sosteniendo por qué no es conveniente la unificación, debiendo reafirmarse la independencia de la responsabilidad contractual, bajo un sistema de remedios.

Palabras clave: Responsabilidad civil; responsabilidad contractual; responsabilidad extracontractual; Código Civil y Comercial (Argentina); unificación; diferenciación.

\section{ABSTRACT}

In the following lines we criticize the objective of unifying the regimes of civil liability, understanding that the non-contractual and contractual statutes can live in harmony in a common regime; but there is an insuperable ab initio difference: the interest in the contract itself as a way of distributing risks, according to the interests of the parties; on the other hand, reparation of the victim's assets in non-contractual matters is known as the interest of conservation of the property and victims rights. We will point out some historical notes and briefly explain how unification was expressed in the new Argentinian Civil Code, in order to endorse why unification is not desirable, and why the independence of contractual responsibility should be reaffirmed under a system of remedies.

Keywords: Civil liability; contractual damages; torts; Civil and Commercial Code (Argentina); unification; differentiation.

\section{INTRODUCCIÓN}

La distinción entre la responsabilidad contractual y extracontractual constituye un asunto inabarcable, tan amplio como desalentador. El debate acerca de la independencia de ambos regímenes o, en cambio, de su necesaria unificación ha sido sempiterno, pedregoso y sin consensos.

La Argentina cuenta, sin embargo, según sugiere el profesor Picasso "con una legislación de avanzada... dado que son muy escasos los ordenamientos jurídicos pertenecientes a la tradición romano-germánica que han alcanzado un grado tal de unificación de las dos esferas". ${ }^{1}$ Esto sería el

\footnotetext{
1 Picasso, Sebastián, "La unificación de la responsabilidad contractual y extracontractual en el Código
} 
"fruto de una larga evolución”, y "Con la unificación de la responsabilidad civil, el flamante Código Civil argentino ha concretado una aspiración de larga data de la doctrina nacional y se ha puesto [a] la vanguardia de los códigos contemporáneos". ${ }^{2}$

La idea de la unificación es vieja, un anhelo para algunos, un error para otros, pero la opción no es inocua, ni tampoco la unificación es total, a pesar que se le quiera. Los Mazeaud señalaban en su Tratado que "no hay diferencia fundamental entre los dos órdenes de responsabilidades. Existen diferencias accesorias". ${ }^{3}$

Con todo, a pesar de los esfuerzos de unificación, parafraseando a un autor francés, el verdor de la responsabilidad contractual pervive, lo que se reconoce en "las diferencias" que "subsisten" entre ambos regímenes, aquellas se resisten a perecer y vuelven a aflorar, aún en los Códigos, escasos, es verdad, que pretenden aunar ambas ramas de la responsabilidad. ${ }^{4}$

En lo que sigue quisiera controvertir esta unificación o, al menos, señalar cierta desconfianza acerca de su conveniencia. Más bien me planteo como un crítico a entender que lo extracontractual y lo contractual puedan convivir en armonía en un régimen común, pues hay una diferencia $a b$ initio insuperable, salvo en un espacio específico que refiere a los daños físicos derivados del incumplimiento contractual en los casos de actividades riesgosas, por ejemplo médica o transporte de pasajeros.

Mientras la responsabilidad contractual se modela conforme el interés del contrato, lo que algunos denominan el fin de protección del contrato, ${ }^{5}$ es decir, lo que resulta esperable de la ejecución o pago y que no se verifica en razón del incumplimiento o, dicho de otra manera, el contrato constituye una forma de distribuir riesgos conforme los intereses de las partes, contratando para el cumplimiento, pero también para el incumplimiento; en cambio, tratándose de la responsabilidad extracontractual, la función que se busca

Civil y Comercial de la Nación”, Suplemento especial, Ed. La Ley, 2014 [151-163]; disponible en línea, LegalPublishing, AR/DOC/3926/2014, pp. 1 y ss.

2 Picasso, cit. (n. 1), p. 10.

3 Mazeaud, Henri; Mazeaud, León; Tunc, André, Traité théorique et pratique de la responsabilité civile délictuelle et contractuelle, Ed. Montchrestien, Paris, 1965, p. 103.

4 Le Tourneau, Philippe, "La verdeur de la faute dans la responsabilité civil (ou de la relativité de son déclin)", Revue Trimestrielle de Droit Civil (RTD civ.), 1998, pp. 505 y ss.

5 Morales Moreno, Antonio Manuel, "El 'propósito práctico' y la idea de negocio jurídico en Federico de Castro", en Morales Moreno, A., La modernización del derecho de obligaciones, Thompson-Civitas, Cizur Menor, 2006, pp. 323-348, en particular, p. 338; Morales Moreno, Antonio M., Incumplimiento del contrato y lucro cesante, Thomson Reuters, Pamplona, 2010, p. 18. 
es, en lo esencial, de reparación de los bienes afectados de la víctima, lo que se conoce como el interés de conservación de los bienes. Parece algo más sencillo, la ausencia de relación precedente entre víctima y victimario permite al momento de aflorar el daño plantearse sólo la cuestión de la indemnización del mismo. ${ }^{6}$

Esta distancia inicial plantea serias controversias a la hora de proceder a la unificación. Aquello que parece sencillo, aunar en la ley los elementos comunes a ambas ramas, sacrifica la complejidad de ambos sistemas, dejando vacíos que - es posible aventurar-los jueces tendrán que satisfacer, reviviendo la diferencia, bajo una unificación más aparente que real. Ya, según veremos, el propio legislador debe inclinarse ante la diferencia, estableciendo reglas particulares, que no es otra cosa que el complemento del régimen de responsabilidad contractual más allá de la indemnización: el sistema de remedios.

Para justificar mi tesis, intentaré en forma muy general dar algunas notas históricas, a lo que seguirá, plasmar cómo se expresó la unificación en el nuevo Código Civil argentino y terminaré afirmando por qué no es conveniente la unificación, debiendo reafirmarse la independencia de la responsabilidad contractual, bajo un sistema de remedios.

\section{NOTAS HISTÓRICAS}

Si bien ha sido controvertida la existencia de la "responsabilidad contractual" en los códigos decimonónicos, en razón que su régimen legal suele aseverarse es fruto de la construcción doctrinal y jurisprudencial a partir de una serie de reglas dispersas a propósito de los efectos de las obligaciones, nadie discute que en el ámbito del contrato resulta necesaria la indemnización de los perjuicios, tanto los intrínsecos como los extrínsecos o, en otra nomenclatura, aquellos consubstanciales y también los consecutivos. ${ }^{7}$

Más allá de la búsqueda del cumplimiento por equivalencia, en caso de imposibilidad sobrevenida material o jurídica, la función indemnizatoria en el ámbito del contrato ha sido un aporte relevante para el edificio de la responsabilidad civil para reparar "brazos y piernas quebradas". Las dificultades

6 Morales Moreno, Incumplimiento..., cit. (n. 5), p. 19.

7 RÉmY, Philippe, "La 'responsabilité contractuelle': histoire d'un faux concept", en Revue Trimestrielle de Droit Civil (RTD civ.), 2006, p. 323; RÉMY, Philippe, "Critique du système français de responsabilité civile", Droit et cultures, 1996, No 31, p. 31; Pizarro Wilson, Carlos, "La influencia del Code en el Código de Bello en derecho de obligaciones. ¿Existe la responsabilidad contractual?”, Cuadernos de Extensión, Universidad de Los Andes, 2004, № 9, pp. 81 y ss. 
probatorias de la culpa dejaron al contrato como una plataforma más viable para la obtención de la reparación, bajo el manto de la presunción de culpa, lo que resultó un camino idóneo ante la ausencia de legislaciones protectoras del trabajador en las postrimerías del siglo XIX y los albores del siglo XX.

La expansión de la "responsabilidad contractual" como mecanismo de reparación, bajo la promoción de la obligación de seguridad, primero respecto de mercaderías y luego en relación a la persona, tratándose del contrato de transporte, azuzada por la distinción entre obligaciones de medio y de resultado, la cual si bien en principio era un intento por resolver un problema de carga de prueba, terminó siendo un alivio probatorio para el acreedor y, más tarde, una forma de ingresar la responsabilidad objetiva en la responsabilidad contractual. En alguna medida es lo que plasma el artículo 1723, al indicar a propósito de la responsabilidad objetiva, que "cuando de las circunstancias de la obligación, o de lo convenido por las partes, surge que el deudor debe obtener un resultado determinado, su responsabilidad es objetiva".

Así las cosas, una jurisprudencia hipertrofiada delineó una responsabilidad contractual, a la imagen de la extracontractual, lo que significó una competencia acérrima entre ambos órdenes de responsabilidad, lo que desencadenó un contenido contractual imaginario a fin de reparar a los acreedores-víctimas del incumplimiento y una creciente importancia del problema de la concurrencia de la responsabilidad civil. El mal llamado cúmulo u opción de responsabilidad.

Habrá que ver, en el caso argentino, cómo los jueces evitan el mismo camino con una regla como la indicada, pues la expresión "las circunstancias de la obligación" para definir la responsabilidad objetiva no me parece muy clara, dejando un espacio importante para la interpretación.

En la evolución planteada, bastante compartida en el sistema continental, ya nada le envidiaba el régimen contractual a aquel extracontractual, pues alcanzaba la misma función indemnizatoria $y$, en ciertos casos, con mayor facilidad, si la obligación era considerada como una de resultado, lo que desencadenaba, como hemos visto, la irrupción de una genuina responsabilidad objetiva. $^{8}$

Incluso los Mazeaud propusieron abolir la regla de previsibilidad propia a la responsabilidad contractual, pretendiendo la necesaria unificación. En España, en la década de los 'ochentas', se planteó una cierta tendencia hacia

8 En Chile, Peñailillo Arévalo, Daniel, "Responsabilidad contractual objetiva”, en Pizarro W., Carlos (Coord.), Estudios de Derecho Civil IV, LegalPublishing, Santiago, 2009, pp. 331 y ss. 
la unificación, aunque moderada, lo que es aún plasmado, por ejemplo, en los dichos de Díez Picazo, cuando asevera la aplicación del régimen contractual si el daño deriva de obligaciones explícitas o deberes accesorios de conducta, encontrándose prohibida la opción si hay una distribución de riesgos acordada.

Sin embargo, desde hace ya algún tiempo, con la denominada modernización del derecho de las obligaciones, se ha producido un cierto cambio de paradigma en la comprensión de qué es lo que debe entenderse por "responsabilidad contractual", la que ya no quedaría limitada a la indemnización de perjuicios por incumplimiento contractual, sino que partiendo de la noción de incumplimiento neutro, es decir, desprovisto de imputación (culpa o dolo), se sitúa al acreedor en un estado que, conforme al interés del contrato, pueda escoger cuál es el remedio o medio de tutela más apropiado para alcanzarlo. Con la expresión "responsabilidad contractual" se comprenden los diversos remedios: el cumplimiento específico, la resolución, la indemnización de perjuicios y otros que, a merced del acreedor, pueden ser utilizados, con ciertos límites, que impidan el abuso.

Con estas notas históricas, acerca de la evolución de ambas ramas de la responsabilidad civil, quedan a mi juicio de manifiesto los dos caminos posibles: la unificación o la independencia.

Es curioso que dos países vecinos, Argentina y Chile, estén tomando caminos tan diversos en relación a la responsabilidad civil. Mientras, en Chile se va asentando en la doctrina y en alguna medida en la jurisprudencia un sistema de remedios frente al incumplimiento contractual, un rechazo o, al menos, una decadencia de la importancia del problema de la concurrencia de la responsabilidad civil; en cambio, acá en Argentina, se pretende atenuar la diferencia, por la vía de la pretendida unificación. Ahora veamos qué tanta unificación hay en el Código Civil argentino.

\section{LA UNIFICACIÓN EN EL CÓDIGO CIVIL ARGENTINO}

¿Qué sucedió en Argentina? Que ha tomado un camino diverso, el que en todo caso pareciera ser consistente con los anhelos de la Doctrina local, que viene preconizando la unificación desde hace más de 30 años.

Podríamos decir que la unificación parte de un precepto general al que se le imputa el efecto de aunar ambos regímenes, lo que repercute en algunas manifestaciones modestas de la decisión, tanto en lo sustantivo como en lo accesorio, lo que no impide la necesidad de afirmar la diferencia, lo que se plantea sería una excepción a la regla.

El supuesto principio. El artículo 1716 indica en relación al deber de 
reparar que "La violación del deber de no dañar a otro, o el incumplimiento de una obligación, da lugar a la reparación del daño causado, conforme con las disposiciones de este Código".

Se dice que aquí estaría el principio de unificación pues con indiferencia de la fuente que causa el daño, procede su reparación. No hay sin embargo, lo que es obvio, una unificación de las fuentes, quedando el origen del daño por separado. Es decir, en la regla misma que se supone establece la unificación se reconoce la diferencia, la causa eficiente difiere, lo que marca en mi opinión la distancia de ambos sistemas.

IV. ¿RÉQUIEM A LA MORA? LA MORA Y EL ARTÍCULO 1748 DEL CÓDIGO CIVIL

"El curso de los intereses comienza desde que se produce cada perjuicio". La mora ya estaba alicaída desde hace un tiempo, al arrinconársela a una función asociada sólo a los daños moratorios, pero como lo indica el artículo 1748, se fija un plazo común para el momento a partir del cual corren los intereses.

Ya sea la mora del deudor o aquella del acreedor, resulta necesario abordar el asunto en forma más integral. Si bien hay razones históricas que explican la paulatina desaparición de la mora creditoris, la que ha quedado más bien limitada al pago por consignación, lo cierto es que contemporáneamente hay una dispersión de instituciones que recurren a la mora tanto desde la perspectiva del deudor como del acreedor, lo que se incrusta en el terreno del contrato, siendo más bien, tratándose de la víctima y su participación en el daño un asunto de causalidad o, si se quiere, de imputabilidad objetiva.

Lo que quiero expresar es que la mora interviene en el ámbito del contrato en relación a varias instituciones; en cambio en sede extracontractual es irrelevante desde la perspectiva del victimario e inoportuna si uno lo analiza desde la perspectiva de la víctima, dado que ésta, en relación a su propio daño, interfiere a través del hecho de la víctima como causal de exoneración total o como factor causal de una menor indemnización si hay exposición de la víctima al daño.

Varias interrogantes quedan pendientes, a pesar de la idea que la mora pasaría al desuetudo. Parece que la mora creditoris debe abordarse en forma más general, al menos en el ámbito contractual, la conducta del acreedor merece una mirada más precisa. La mora creditoris involucra entender el hecho del acreedor como causal de exoneración al romper el vínculo causal, también justifica el pago por consignación, permite entender en alguna medida la excepción de contrato no cumplido y el impedimento para el 
devengo de la indemnización por el retardo. No basta con la regla unificadora del artículo 1748, ni tampoco con aquella del hecho del damnificado prevista en el artículo 1729, que por cierto resulta aplicable al contrato, pero no abarca la complejidad de la intervención del acreedor ya sea como obstáculo al cumplimiento o causante del mismo.

\section{LA PLURALIDAD DE RESPONSABLES}

Se ha planteado, a partir del artículo 1716, en relación al artículo 1751, que la solidaridad regiría en la responsabilidad contractual si el daño cuya indemnización se pretende tiene una causa única, en cambio si son causas distintas, la obligación será concurrente. "Todos los deudores contractuales responderán solidariamente si su crédito tiene una causa única", y se agrega "de este modo, el principio general de la simple mancomunación queda acotado a la pretensión de cumplimiento específico, o bien a aquellos casos en que se reclame el contravalor dinerario de la prestación (aestimatio rei)".

La solución puede ser saludada con beneplácito. Habría una misma regla para el caso que tratándose de una misma obligación existiere pluralidad de responsables. Se trata de la hipótesis en que un contrato, respecto a unas mismas obligaciones, tiene dos o más deudores obligados al unísono. Sin embargo, la pregunta que surge es cuál es la razón para que atendida la unidad de la deuda y pluralidad de responsables, los daños ocasionados sean de cargo de cualquiera, aun en el caso que sólo uno de los deudores sea responsable del daño por su culpa. La idea de solidaridad se podría comprender respecto de la aestimatio rei -la equivalencia de la prestación-, por ejemplo, en caso de imposibilidad sobrevenida, pero no estoy tan convencido que se justifique respecto a los daños consecutivos, pese a lo dispuesto en el artículo 838 del Código argentino.

\section{LA PRESCRIPCIÓN}

El artículo 2561 señala un plazo común a ambos tipos de responsabilidad de tan solo tres años. Establecer un tiempo único para que se entienda extinta la acción indemnizatoria contractual o extracontractual no ha sido nunca un asunto espinudo. Más bien los problemas que giran en torno a este modo de extinguir refieren al cómputo del plazo o dies a quo. ¿Desde cuándo se cuenta el plazo de tres años?

9 Picasso, cit. (n. 1), p. 5. 
Acá debe considerarse el artículo 2554 del nuevo Código: "El transcurso del plazo de prescripción comienza el día en que la prestación es exigible".

En el ámbito extracontractual suele indicarse que el plazo debe computarse desde la manifestación del daño, en cambio la acción indemnizatoria contractual corre desde que la obligación sea exigible. A esto se agrega que el mismo Código en hipótesis contractuales establece términos distintos, por ejemplo daños derivados de accidentes y enfermedades del trabajo o lo que refiere al contrato de transporte (artículo 2562, letras b) y d)).

Me parece que ciertas particularidades del daño en el ámbito extracontractual han justificado un tratamiento especial. La idea de exigibilidad de la obligación es propia al ámbito contractual; en cambio, es la manifestación del daño lo que suele marcar el cómputo del plazo en el terreno aquiliano.

\section{LA EXTENSIÓN DEL DAÑO INDEMNIZABLE}

Se ha afirmado que acá habría un mismo criterio para ambos regímenes. El artículo 1726, a propósito de la relación causal, indica que "son reparables las consecuencias dañosas que tienen nexo adecuado de causalidad con el hecho productor del daño. Excepto disposición legal en contrario-quizá debió agregar también convencional-, se indemnizan las consecuencias inmediatas y las mediatas previsibles". El artículo 1727 recoge la teoría de la causalidad adecuada bajo el manto de la normalidad, en una enmarañada redacción que distingue entre "consecuencias inmediatas", "consecuencias mediatas" y, por último, aquellas "consecuencias casuales". Pero, al menos en lo que importa a la indemnización de los daños por incumplimiento contractual, no podía soslayarse la regla de previsibilidad: "En los contratos se responde por las consecuencias que las partes previeron o pudieron haber previsto al momento de su celebración", salvo dolo, en cuyo caso la mirada alcanza también la época del incumplimiento.

En el ámbito de la causalidad, más que unificación o diferencia entre ambos estatutos, lo relevante es la forma en que se define la extensión del daño indemnizable. De manera tradicional se ha afirmado que lo extracontractual permite indemnizar daños previstos e imprevistos; en cambio, si el daño tiene origen en el incumplimiento contractual, sólo cabría la indemnización de los daños previstos a la época de la celebración del contrato, salvo dolo. Es la diferencia que recoge el artículo 1728 bajo el título de "Previsibilidad contractual". Con la aplicación de las teorías de imputabilidad objetiva en la 
responsabilidad extracontractual, a través de criterios como el incremento del riesgo de vida u otros, que reconoce el carácter normativo de la causalidad, se ha intentado construir un parámetro para dilucidar el elemento causal en sede contractual bajo el supuesto de la norma contractual. La construcción del elemento normativo es diversa en ambos regímenes, pues la existencia del contrato, no sólo en su contenido, sino que en el proceso de formación que permite auscultar el propósito práctico al momento de contratar, define los intereses asegurados y, por ende, qué daños quedan garantizados por el acuerdo. El proceso para dilucidar qué daños se indemnizan no es tan distinto, sólo que la forma para llevarlo a cabo difiere.

Todavía en relación al daño, sabida es la discusión argentina sobre si corresponde diferenciar el valor económico de la prestación o cumplimiento por equivalencia de los daños consecutivos al incumplimiento o si debe tratarse todo como una indemnización de perjuicios. La unidad o dualidad del daño en sede contractual. Las reglas del Código no son tan claras. Mientras el artículo 730 letra c) pareciera bregar por la unidad del concepto, lo mismo en caso de imposibilidad sobrevenida por culpa, conforme lo dispuesto en el artículo 955 in fine. Estas reglas contrastan con lo dispuesto en los artículos 781,838 y 1114 .

\section{EL SISTEMA DE REMEDIOS}

La responsabilidad contractual no es sólo una cuestión de indemnización de perjuicios. La idea de responsabilidad contractual, me parece, no puede circunscribirse a una mera cuestión indemnizatoria una vez incumplido el contrato. Frente al incumplimiento contractual, el acreedor no dispone sólo de la indemnización como remedio, sino que conforme convivan las alternativas de que dispone por la ley dispositiva, la resolución o el cumplimiento específico o, aún más, la acción de rebaja del precio, sin considerar lo que puedan haber dicho las partes en virtud de la libertad contractual: cláusulas resolutorias, estipulaciones de exoneración o limitación de la indemnización, las estipulaciones relativas a la fuerza mayor, el hecho del acreedor, la excepción de contrato no cumplido, etc. El engranaje contractual, como podemos constatar, es más complejo que pensar sólo en la indemnización derivada del incumplimiento. Por lo mismo resulta más apropiado entender el fenómeno del incumplimiento contractual de manera más amplia, considerando las diversas alternativas a favor del acreedor. Conforme ya indicamos "la responsabilidad contractual toma en consideración, fundamentalmente, el interés que surge del contrato (fin de protección del contrato), los beneficios o 
las ventajas que cada contratante tiene derecho a obtener de él, frustrados por el incumplimiento". En contraste a esto, "la responsabilidad extracontractual, en cambio, considera exclusivamente el interés de conservación de los bienes de un sujeto. Se orienta a la reparación del daño proveniente de la lesión de dichos bienes". ${ }^{10}$

La idea de una responsabilidad contractual bajo un supuesto de incumplimiento neutro, sin referencia a la imputabilidad, que habilite al acreedor a escoger cuál remedio es más apropiado, atendido el fin del contrato, para alcanzar el propósito práctico del mismo, parece un esquema mejor adaptado a la necesaria distribución de riesgos que involucra un acuerdo contractual. Al unificar se soslayan las particularidades del contrato, en cuanto mecanismo de organización del riesgo. La indemnización de perjuicios se le erige en forma independiente de los otros remedios, lo que no es apropiado, si consideramos que puede acompañar el cumplimiento específico o la resolución y, además, debe compatibilizarse con la rebaja del precio. Las sutilezas que se generan a partir de reconocer que la indemnización puede ser autónoma o accesoria a las otras acciones contractuales, importa un análisis de la reparación del daño diversa. No puede evitarse que el lucro cesante sea diverso según los tipos de contrato de que se trate, por ejemplo, contratos de intercambio o de colaboración. O que los efectos de la resolución, entendidos como una operación de liquidación económica modelen también la indemnización de perjuicios consecutiva, según haya un efecto retroactivo total, parcial o atenuado. Todavía el deber de minimizar el daño debe engarzarse con la indemnización de perjuicios, teniendo una diversa justificación y aplicación en el terreno extracontractual. Por último, aunque no sea exhaustivo, la fuerza mayor, en cuanto excusa de indemnización difiere según nos encontremos en el ámbito del contrato o no, pues la resistibilidad o previsibilidad se miden, conforme un patrón de diligencia, en forma distinta según haya o no contrato.

En definitiva, hay una pluralidad de particularidades que arrancan en la fuente diversa del daño, según haya o no contrato, lo que reconoce el artículo 1716, y que termina con la extensión del daño indemnizable y con su necesaria incardinación con los demás remedios contractuales.

Así como "la cuadratura del círculo no habría parecido tan plausible a los griegos de no haber sido por el hecho de que Hipócrates de Quíos demostró que ciertas figuras curvilíneas construidas a propósito por él, llamadas lúnulas, podían cuadrarse", la idea de unificar la responsabilidad

\footnotetext{
${ }^{10}$ Morales Moreno, Incumplimiento..., cit. (n. 5), p. 18 y 19.
} 
constituye una ilusión, que nos da algunos artículos del nuevo Código Civil argentino, pero aflorando, escarbando nada más un poco, la particularidad de la responsabilidad contractual, la que creo merece un espacio propio. Como lo sugiere el profesor Picasso en su tesis doctoral a propósito de la responsabilidad contractual y sus lazos con aquella extracontractual, "la multiplicidad en la singularidad" constituye una alternativa, la pregunta es si este nuevo Código ha sido fiel a esa propuesta.

\section{BIBLIOGRAFÍA}

Código Civil y Comercial de la Nación (Argentina), Ley 26.994 de 2015. Disponible en portal de Información Legislativa 'InfoLeg' del Ministerio de Justicia de la Nación Argentina, en línea: http://servicios.infoleg.gob.ar/ infolegInternet/anexos/235000-239999/235975/norma.htm

Le Tourneau, Philippe, "La verdeur de la faute dans la responsabilité civil (ou de la relativité de son déclin)", Revue Trimestrielle de Droit Civil. (RTD civ.), 1998, pp. 505 y ss.

Mazeaud, Henri; Mazeaud, León; Tunc, André, Traité théorique et pratique de la responsabilité civile délictuelle et contractuelle, Ed. Montchrestien, Paris, 1965, p. 103.

Morales Moreno, Antonio M., “El 'propósito práctico' y la idea de negocio jurídico en Federico de Castro", en Morales Moreno, A., La modernización del derecho de obligaciones, Thompson-Civitas, Cizur Menor, 2006, pp. 323-348.

Morales Moreno, Antonio M., Incumplimiento del contrato y lucro cesante, Thomson Reuters, Pamplona, 2010.

Peñailillo Arévalo, Daniel, "Responsabilidad contractual objetiva”, en Pizarro W., Carlos (Coord.), Estudios de Derecho Civil IV, LegalPublishing, Santiago, 2009, pp. 331 y ss.

PicAsso, Sebastián, "La unificación de la responsabilidad contractual y extracontractual en el Código Civil y Comercial de la Nación”, Suplemento especial, Ed. La Ley, 2014 [151-163]; disponible en línea, LegalPublishing, AR/DOC/3926/2014, pp. 1 y ss.

Pizarro Wilson, Carlos, "La influencia del Code en el Código de Bello en derecho de obligaciones. ¿Existe la responsabilidad contractual?”, Cuadernos de Extensión, Universidad de Los Andes, 2004, № 9, pp. 81 y ss. 
RÉmY, Philippe, “La 'responsabilité contractuelle': histoire d'un faux concept", en Revue Trimestrielle de Droit Civil (RTD civ.), 2006, p. 323.

RÉmY, Philippe, "Critique du système français de responsabilité civile", Droit et cultures, 1996, No 31, p. 31 ss. 